\title{
Design of Steam Turbine for Electric Power Production Using Heat Energy from Palm Kernel Shell
}

\author{
Buliaminu Kareem ${ }^{*}$, Theophilus Ewetumo², Michael K. Adeyeri' ${ }^{1}$, Akinlabi Oyetunji ${ }^{3}$, \\ O. E. Olatunji ${ }^{1}$
}

${ }^{1}$ Department of Industrial and Production Engineering, The Federal University of Technology, Akure, Nigeria ${ }^{2}$ Department of Physics, The Federal University of Technology, Akure, Nigeria

${ }^{3}$ Department of Metallurgical and Materials Engineering, The Federal University of Technology, Akure, Nigeria

Email: *bkareem@futa.edu.ng

How to cite this paper: Kareem, B., Ewetumo, T., Adeyeri, M.K., Oyetunji, A. and Olatunji, O.E. (2018) Design of Steam Turbine for Electric Power Production Using Heat Energy from Palm Kernel Shell. Journal of Power and Energy Engineering, 6, 111-125.

https://doi.org/10.4236/jpee.2018.611009

Received: October 28, 2018

Accepted: November 27, 2018

Published: November 30, 2018

Copyright $\odot 2018$ by authors and Scientific Research Publishing Inc. This work is licensed under the Creative Commons Attribution International License (CC BY 4.0).

http://creativecommons.org/licenses/by/4.0/

\begin{abstract}
The steam turbine is a prime mover that converts kinetic energy in steam into rotational mechanical energy through the impact or reaction of the steam against the blades. The aim of this study is to design a steam turbine for a small scale steam power plant with target of producing electricity. The turbine is driven by the heat energy from palm kernel shells as a renewable energy source obtained at a lower or no cost. The study was concentrated on design of turbine elements and its validation using computer packages. Specifically, the microturbine design was limited to design, modeling, simulation and analysis of the rotor, blades and nozzle under the palm kernel shell as fuel for the micro power plant. In blade design, stress failures, efficiency and blade angle parameters were considered. In casing volume design, the overall heat transfer and mean temperature, and different concepts were applied. The thermal distribution on stator and rotor was considered in order to determine its level of tolerance. The design software packages used for design validation were Solidworks and Comsol Multiphysics for analysis. Simulation results showed that the designed steam turbine can adequately tolerate change in stress/load, torsion/compression, temperature and speeds.
\end{abstract}

\section{Keywords}

Palm Kernel Shell, Steam Turbine, Power Plant, Design Software, Renewable Energy

\section{Introduction}

A steam turbine can be defined as a form of heat engine in which the energy of 
the steam is transformed into kinetic energy by expansion through nozzles, and the kinetic energy of resulting jet is in turn converted into force on rings of blades mounted on a rotating disc. Steam micro-turbines are considered to be such devices which produce output power of the order of a few kWs. Steam turbines on micro-power plants are capable of delivering electric power ranging 1 $6 \mathrm{~kW}$ [1]. For optimal electricity production, a thermal power plant (TPP) is chosen to encompass effective and robust choice of facilities. The turbine and the alternator are facilities of importance in the constitution of a TPP [2]. The ability of turbine to generate a rotary motion made it suitable to drive an electrical generator.

In the search for an alternative source of energy, palm kernel shell was found to be a well-known biomass product because of its higher heat energy or calorific value. Palm kernel shell has gained it status as a biofuel resource for biomass product which is cheap, readily available and due to its high calorific value, its properties can be utilized in creation of an efficient micro-power plant which comprises of five main components which are the boiler, turbine, generator, condenser and pump. It is therefore beneficial to produce high pressure steam, and let it expand to the desired pressure and temperature through a turbine or to extract part of the steam from the turbine before it reaches the low-pressure stage and its rotary motion is used to drive the generator to produce electricity. The aim of this research is to conduct a design analysis for an efficient steam turbine for a palm kernel shell (PKS) fuelled micro power plant which will generate $5 \mathrm{~kW}$ electricity. The specific objectives of this research are to: design and analyze a steam turbine based on predetermined design considerations and materials selection criteria; and evaluate the performance of the steam turbine in propelling the generator to produce $5 \mathrm{~kW}$ of electricity. The design analysis has formed a baseline for the development of a steam turbine with target of producing $5 \mathrm{~kW}$ of electricity in micro power plant using PKS as fuel. The research is limited to design, simulation and analysis of the rotor, blades and nozzle of the steam turbine.

Palm kernel shell (PKS) is the main by-product of palm kernel oil production. Palm kernel is kernel from oil palm fruit. After the oil palm fruit went through the palm oil process, the kernels are separated and kernel oils distilled [3]. Oladosu and Oladosu et al. [4] [5] [6] optimized the combustion of palm kernel shell (PKS) in a grate furnace for superheated steam generation. The outcome supported the use of PKS for power generation because of its higher heating value, but the study failed to implement same. Oladosu et al. [7] [8] [9] used computer based approach to design palm kernel shell combusting furnace for generating a desired amount of electricity. By way of backward calculation approach, standard design equations were used to size furnace, Turbine and other components. The results showed that to generate $5 \mathrm{~kW}$ of electricity from palm kernel shell, $5.5 \mathrm{~kW}$ turbine is required. The study failed to carry out comprehensive design of the turbine to utilized heat/steam produced from combustion 
system. This is the area this study attempted to address.

Chandra et al. [10] analyzed the behavior of rotors on different mechanical and thermal-mechanical analyses to find out the better one out of the solid rotor and the hollow rotor in terms of ease of manufacturing and failure. Further analysis based on thermal and structural distribution on blades was carried out [11]. This study is deficient by not taking a step ahead in analyzing critical turbining parameters, which are stress/load, torsion/strain, temperature, and speed tolerance. Chenduran [12] analyzed, in blade design, stress failures, efficiency and nozzle angle using solidworks software. Many designs have been carried out on turbines ranging from single-stage axial-flow turbines, two-stage axial-flow turbines, radial-flow turbines to radial-axial-flow turbines [1], efforts in the area of micro-turbine design for micro-power plant have been scanty. This is the germane area in which this study is posed to contribute.

\section{Materials and Methods}

\subsection{Design Concepts}

In the design of a steam micro-turbine, there are major parameters to be considered. The input parameters included the superheated steam temperature, pressure, mass flow rate and other specific properties. The required output to achieve necessary power supply required are the angular velocity, speed, and torque. Others include the type of cycle for effective conversion, the classification of the steam turbine, the blade profile design and arrangement, the number of stages required for effective steam pressure utilization, nozzle and condenser design. The turbine design process has a series of steps as enumerated in Figure 1. Turbine specifications; these include the rotational speed or speed range, steam pressures at the turbine's inlet and exhaust, steam temperature at the turbine inlet, and the desired power output. Determination of staging based on the turbine specifications; the turbine designer makes some basic decisions on which the flow path design is built, such as degree of reaction, desired blade peripheral speed, stage diameters, and number of stages in the turbine. At this stage, the number of rows of stationary and moving blades is established. Determination of optimum flow passage angles by creating velocity diagrams for each stage based on the mean diameter of the flow path to determine appropriate airfoil entrance and exit angles, for best performance at the design. Detailed stage design determines the quantity and the size (that is the width or chord) of the blades (short constant section airfoils or a series of radial stations for tall blades with twisted airfoil shapes). Reliability evaluation ensures that steady steam bending and centrifugal forces are within acceptable limits. The vibratory characteristics of the blades are predicted and compared with the frequency and shape of unsteady forces from a variety of sources that acted on the blades.

Steam turbine depends completely upon the dynamic action of the steam. Working principle of the power in a steam turbine is obtained by the rate of 


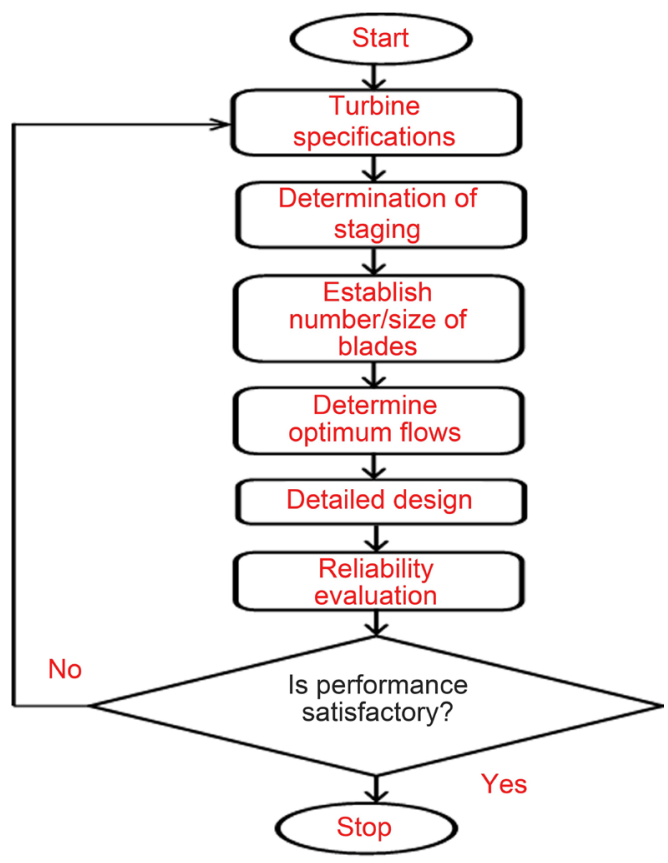

Figure 1. Design flow chart for the micro-turbine for $5 \mathrm{~kW}$ electricity production.

change in momentum of a high velocity jet of steam and hit on a curved blade, which is free to rotate based on the Newton's second law's rate of change of momentum. The blades are attached to the rotor shaft. The resultant of blade forces is converted into shaft power to drive the load. The loading on a rotating turbine blade is composed of centrifugal force due to rotation, bending force due to the fluid pressure and change of momentum. The design specifications by taking cognizance of the designed steam boiler where palm kernel shell was used as heat energy source [5] [6] [8] [9] was applied in this study (Table 1). The specifications can sustain a multistage impulse flow steam micro turbine of power $5.5 \mathrm{~kW}$, steam mass flow rate $0.0275 \mathrm{~kg} / \mathrm{s}$, expected efficiency of $75 \%$, inlet temperature $400^{\circ} \mathrm{C}$ and speed (greater than $1500 \mathrm{rpm}$ ).

\subsection{Turbine Design Calculation}

Based on the design specifications given in Table 1, standard equation (1) was used to determine the output steam temperature and enthalpy with $\mathrm{Q}$ as the turbine power $(5.5 \mathrm{~kW}), \mathrm{m}$ as mass flow rate $(0.0275 \mathrm{~kg} / \mathrm{s}), \Delta \mathrm{H}$ as change in enthalpy $(200 \mathrm{~kJ} / \mathrm{kg})$ and $\mathrm{H}_{1}$ as inlet enthalpy at inlet temperature of $400^{\circ} \mathrm{C}(2899.2$ $\mathrm{kJ} / \mathrm{kg}$ ) [13];

$$
\begin{gathered}
\mathrm{Q}=\mathrm{m}(\Delta \mathrm{H}) \\
\mathrm{H}_{2}=\mathrm{H}_{1}-\Delta \mathrm{H}=2699.2 \mathrm{~kJ} / \mathrm{kg} .
\end{gathered}
$$

The velocity diagram was used as standard tool for determining turbine performance and flow parameters [14] [15] [16]. Critical flow parameters considered and designed for were the actual and relative velocities of the turbine blades and the steam, which in turn determined the power of the turbine [17] 
Table 1. Micro steam-turbine design specifications.

\begin{tabular}{cccc}
\hline \multirow{2}{*}{ Description } & \multicolumn{3}{c}{ Design specifications } \\
\cline { 2 - 4 } & Specification & Description & Specification \\
\hline Turbine type & $\begin{array}{c}\text { Axial flow, impulse flow } \\
\text { steam nicro turbine }\end{array}$ & Stage & Multistage \\
Expected power & $5.5 \mathrm{~kW}$ & Rotation speed & $>1500 \mathrm{rpm}$ \\
Steam mass flow rate & $0.0275 \mathrm{~kg} / \mathrm{s}$ & Turbine inlet temperature & $400^{\circ} \mathrm{C}$ \\
Efficiency & $75 \%$ & Specific heat capacity of steam & $0.03571 / \mathrm{mol} \cdot{ }^{\circ} \mathrm{C}$ \\
\hline
\end{tabular}

[18]. In an impulse turbine all the enthalpy change takes place in the stationary nozzles. This action has made the impulse stages liable to low axial thrust loads on the rotor. The velocity diagram for the impulse turbine with directions of movement, angle of incidence or contact and the resulting velocities for Euler's equation are in Figure 2, where $\mathrm{V}$, is absolute inlet steam velocity; $\mathrm{V}_{1}$, is relative inlet steam velocity (to moving blades); $\mathrm{W}$, is blade tangential speed; $\mathrm{V}_{2}$, is relative exit steam velocity (neglecting losses); $\mathrm{V}_{3}$, is absolute exit steam velocity; $\theta$, is vector difference between $\mathrm{V}$ and $\mathrm{W}$ or nozzle discharge angle; $\theta_{1}$, is vector difference between $\mathrm{V}_{1}$ and $\mathrm{W} ; \theta_{2}$, is vector difference between $\mathrm{V}_{2}$ and $\mathrm{W}$; and $\theta_{3}$, is vector difference between $\mathrm{V}_{3}$ and $\mathrm{W}$.

On these bases, absolute inlet velocity, $\mathrm{V}$ of the impulse turbine was obtained from Equation (2), while the vector difference (nozzle discharge angle), $\theta$ was estimated as $30^{\circ}$ using Equation (3) (giving efficiency of turbine, $\eta$ as $75 \%$. This outcome rendered optimum absolute inlet steam velocity, $\mathrm{V}_{\text {optimum }}$ to be 0.5 using Equation (4).

$$
\begin{gathered}
\mathrm{V}=44.7 \times(\Delta \mathrm{H})^{0.5} \\
\eta=\cos ^{2} \theta \\
\mathrm{V}_{\text {optimum }}=2 \mathrm{~W} / \operatorname{Cos} \theta(\text { that is } \mathrm{W} / \mathrm{V}=0.5)
\end{gathered}
$$

By considering minimum rotational output speed ( $>1500 \mathrm{rpm}$ ), while input speed of $8000 \mathrm{rpm}(\dot{\omega}, 942.48 \mathrm{rad} / \mathrm{s})$ were considered over the linear velocity required from the blade mounted on rotor diameter $300 \mathrm{~mm}(\mathrm{r}, 150 \mathrm{~mm})$ obtained from $\mathrm{W}=\mathrm{r} \omega$, using a rotor diameter of $300 \mathrm{~mm}$ as $142 \mathrm{~m} / \mathrm{s}$. Hence, the absolute velocity of steam flow is $326.48 \mathrm{~m} / \mathrm{s}$ while the resultant blade velocity is $142 \mathrm{~m} / \mathrm{s}$. Followed from Equations (2)-(4), $\Delta \mathrm{H}_{\text {stage }}$ was estimated as $53.34 \mathrm{~kJ} / \mathrm{kg}$ making a total of Ns equal to 5 stages under the $\Delta \mathrm{H}_{\text {avail }}$ of $266.67 \mathrm{~kJ} / \mathrm{kg}$ available. The blade of the turbine was airfoil-designed to enable maximum use of the energy from steam for rotation [19].

The geometry of entry and exit of steam into/from the blade was optimized by considering the pitch and chord lengths of the blades (Figure 3). The principal parameters considered in the design are blade profile (airfoil cross section), blade solidity/pitch to chord ratio, blade aspect ratio/height to chord ratio, and blade stacking. Standard designed procedures of the stated parameters were modified to optimally meet the micro power requirement level of the turbine. 


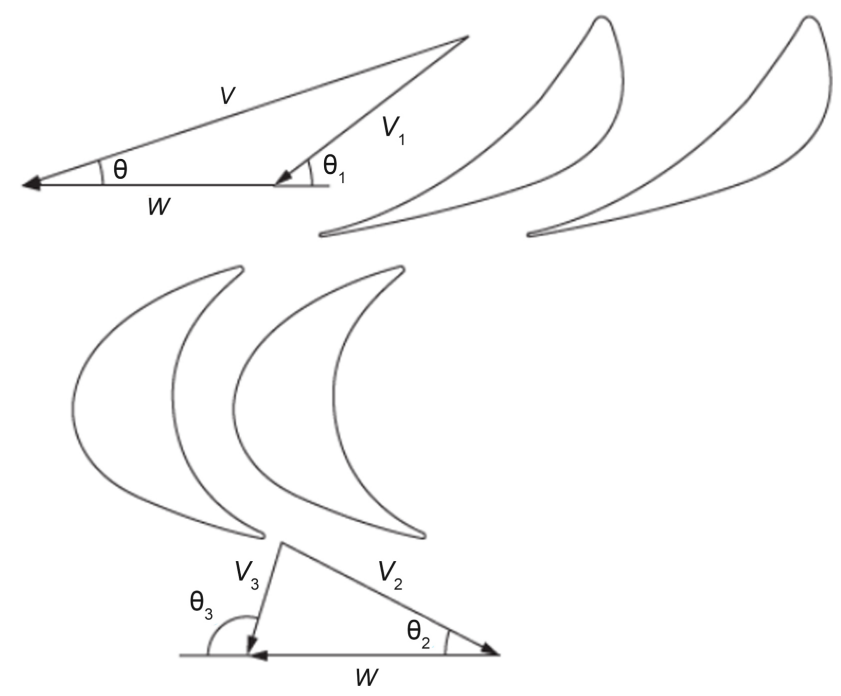

Figure 2. Velocity diagram for blade, inlet sream, exit steam and tangential velocities.

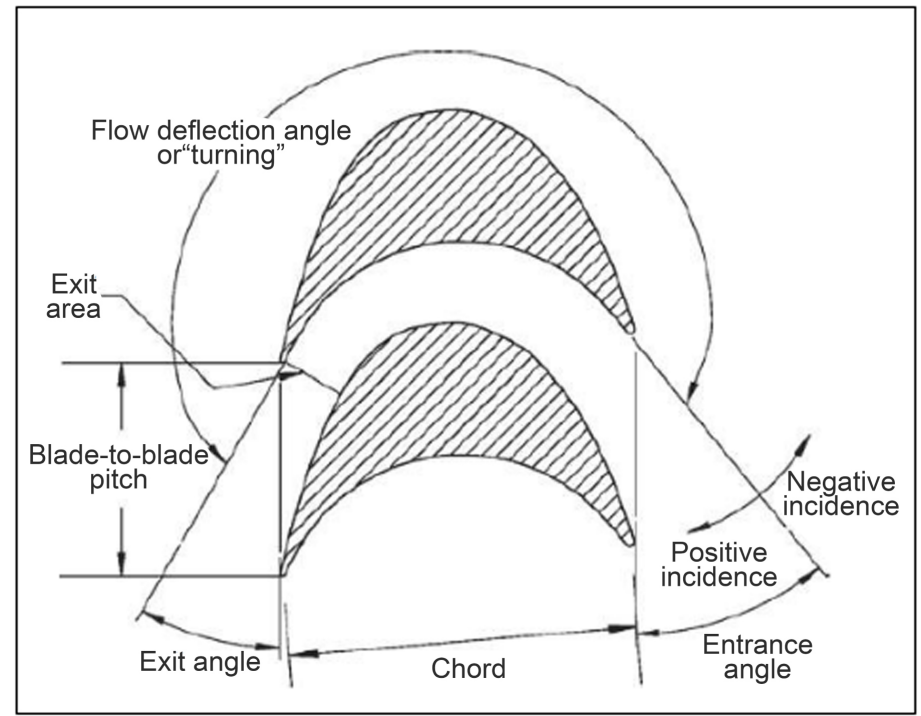

Figure 3. Airfoil geometry.

Once the optimum solidity is determined for a selected airfoil, the number of blades in the row can be calculated by dividing the stage circumference at mean blade diameter by the optimum pitch. The aspect ratio was determined as a ratio of the nozzle and the blade heights of the micro-turbine system. Since the steam has a specific volume of $0.4627 \mathrm{~m}^{3} / \mathrm{kg}$ at inlet, massflow rate of $0.0275 \mathrm{~kg} / \mathrm{s}$, and the volumetric flow rate of $0.0127 \mathrm{~m}^{3} / \mathrm{s}$ [5] [6] [8] [9], good nozzle spacing (inlet to outlet) was needed to reduce unsteady loading on the blades. These irregularities were reduced by making the pitch equal to the pitch of the blades. The height of $16 \mathrm{~mm}$ was considered appropriate with a setback of $5 \mathrm{~mm}$. By considering the expansion of the steam after leaving the nozzle the height of $20 \mathrm{~mm}$ was designed for the blades. The choice is close to the common practice in impulse turbine designs in which the aspect ratio of 1, having the chord of $20 \mathrm{~mm}$ 
and pitch of $20 \mathrm{~mm}$ were used. Figure 4 illustrates design of the nozzle geometry of the micro-turbine.

In the presence of mean blade path diameter, $D_{m},(0.3)$, blade spacing (pitch), $s$ (0.02), the number of blades $\mathrm{N}_{\mathrm{b}}$ was determined using Equation (5) as 94 . The shaft diameter was determined to be $19.74 \mathrm{~mm}(25 \mathrm{~mm})$ for mild steel using Equation (6) [15], given that torque, T transmitted by the shaft is in $81.58 \mathrm{Nm}$, yield stress for mild steel $d_{o}$ is $200 \mathrm{~N} / \mathrm{mm}^{2}$ and $\pi, 3.142$ is a constant

$$
\begin{aligned}
& \mathrm{N}_{\mathrm{b}}=\frac{2 \pi D m}{s} \\
& d^{3}=\frac{16 \mathrm{~T}}{0.27 \pi d_{o}}
\end{aligned}
$$

Performance (reliability) evaluation of the design was carried out using modelling and simulation technique via Solidworks and Comsol Multiphysics analytical software. In the micro turbine design, the analyses covered the blade, shaft and nozzle design. In blade design parameters, stress failures, efficiency were analyzed. In casing volume design, the overall heat transfer in the volume and mean temperature difference concepts were evaluated. The thermally induced stresses in a turbine stator blade are analyzed to determine tolerance and reliability level.

\subsection{Material Selection}

The selection of materials for different parts of the turbine depends on the strength or tension/compression the component can withstand, heat transfer coefficient and thermal resistivity makes sure that the total weight must be minimal. In selecting materials, high consideration was given to lightweight materials that can withstand stress and strain of that particular component compared to heavy or bulky materials. After thorough analysis, the materials chosen with estimated cost for the components and their proposed fabrication methods are given in Table 2 and Table 3, respectively.

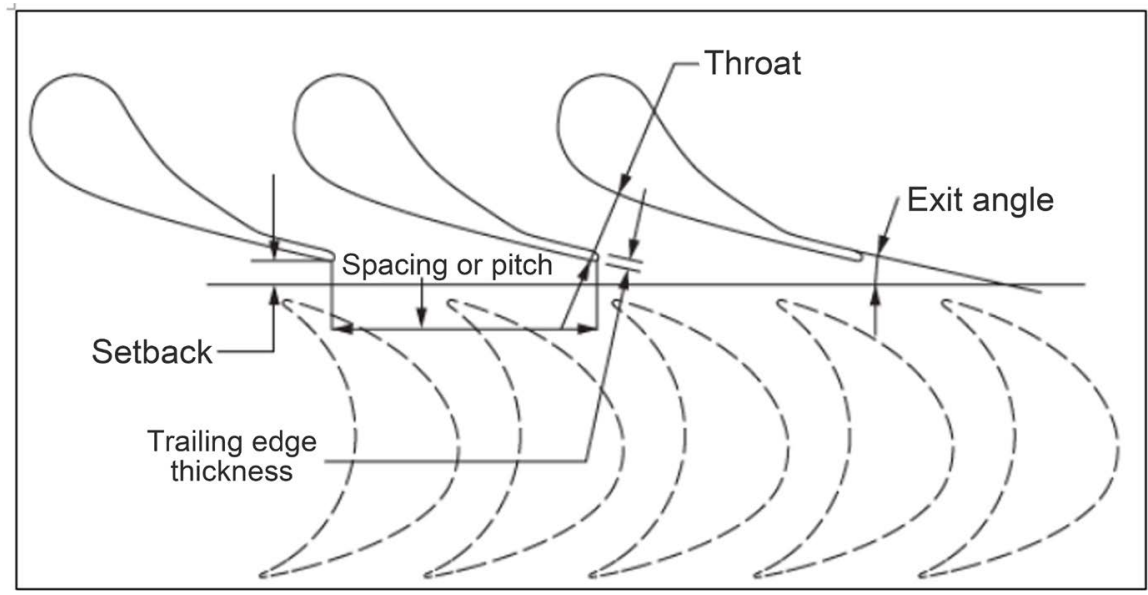

Figure 4. Design of Nozzle geometry. 
Table 2. Material selection for the turbine components and fabrication method.

\begin{tabular}{ccc}
\hline \multirow{2}{*}{ Components } & \multicolumn{2}{c}{ Material used and fabrication method } \\
\cline { 2 - 3 } & Material used & Fabrication method \\
\hline Rotor & Austenitic stainless steel & Welding \\
Stator & Austenitic stainless steel & Welding \\
Shaft & Mild steel & Machining \\
Structure & Insulated stainless steel & Welding \\
Inlet nozzle & Stainless steel & Welding/machining \\
Exist nozzle & Stainless steel & Welding/marching \\
\hline
\end{tabular}

Table 3. Bill of engineering material and evaluation for the turbine.

\begin{tabular}{cccc}
\hline \multirow{2}{*}{ Part description } & \multicolumn{3}{c}{ Cost of production (Naira, N, Nigerian currency) } \\
\cline { 2 - 4 } & Cost $(\mathrm{N})$ & Part description & Cost (N) \\
\hline Shaft & 45,000 & Rotor & 30,000 \\
Spur gear & 15,000 & Bearings & 25,000 \\
Stainless plate & 70,000 & Others & 50,000 \\
Reduction gear & 45,000 & Total cost & 280,000 \\
Mini power house & 310,000 & Grand total cost & 590,000 \\
\hline
\end{tabular}

\section{Results and Discussion}

In this microturbine design using Solidworks and Comsol Multiphysics analytical software, the results obtained mainly covered the blade, shaft and nozzle design. In blade design parameters, stress failures, efficiency and inlet/outlet angle were considered and the outcome is illustrated in Figure 8. In casing volume design, the overall heat transfer in the volume and mean temperature different concepts were analyzed and the results are given in Figure 5 and Figure 6. Figure 7 gives the outcome of the stress analysis of the blade in withstanding the forces. The outcome interface of thermally induced stress on the turbine stator blade is presented in Figure 5.

The thermal stress on the analyzed stator shows that the heat distribution in the stator, represented by colour gradients indicated red as the highest thermal stress temperature of $6.018 \mathrm{e}+002 \mathrm{~K}$ under COMSOL Multiphysics analysis (Figure 5). This shows that the stator cannot be majorly affected by heat or overheated in the turbining process when operated within the temperature $5.231 \mathrm{e}+002 \mathrm{~K}$ and $6.018 \mathrm{e}+002 \mathrm{~K}$ (Figure 6). The result of the thermal analysis carried out on the stator shows that the stator cannot be affected by heat, stress and strain during torsion/compression process (Figure 7) with a strain tolerance ranging from $1.46008 \mathrm{e}-012$ to $1.86427 \mathrm{e}-008$. The stress/heat analysis outcome on the turbine rotor and blades indicated allowable heat load/temperature of $250^{\circ} \mathrm{C}$ with maximum heat flux of $200 \mathrm{~W} / \mathrm{m}^{2}$ (Figure 8). Heat load beyond the stated allowances open the design to imminent failure. The modified flow conditions adopted has 


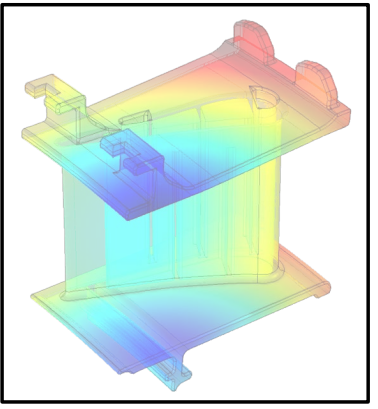

Figure 5. Thermal stress simulation on stator.

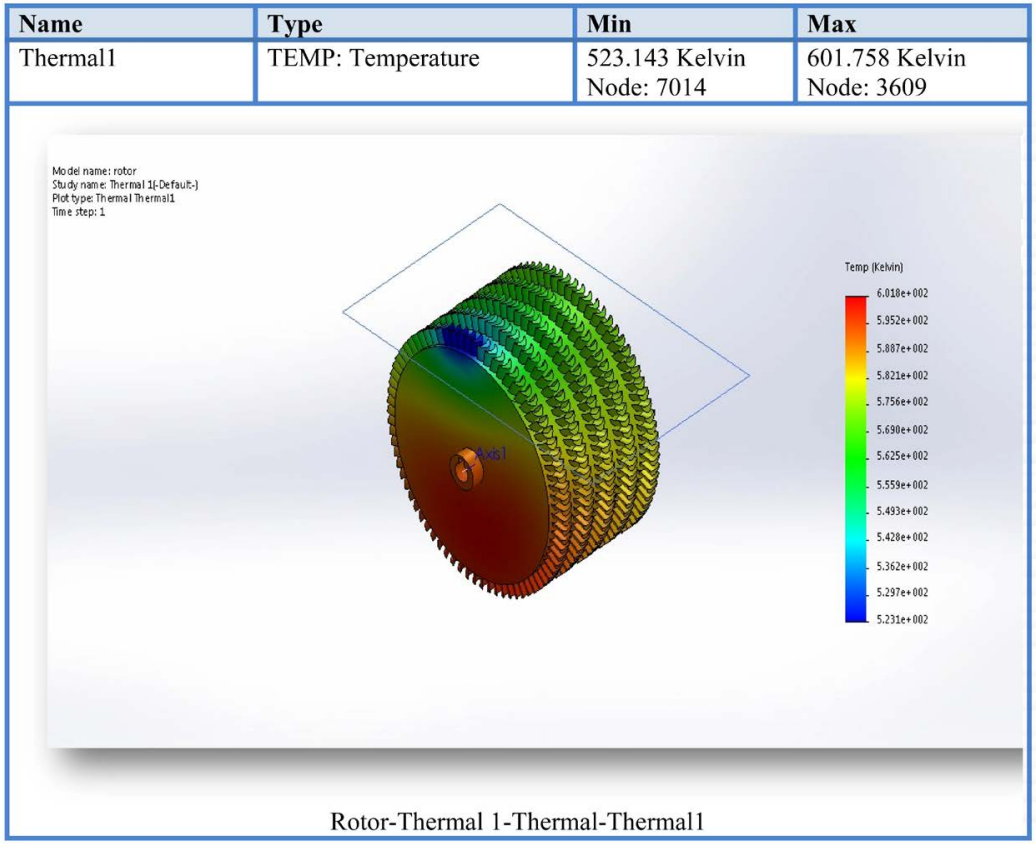

Figure 6. Thermal simulation analysis on the turbine rotor blades.

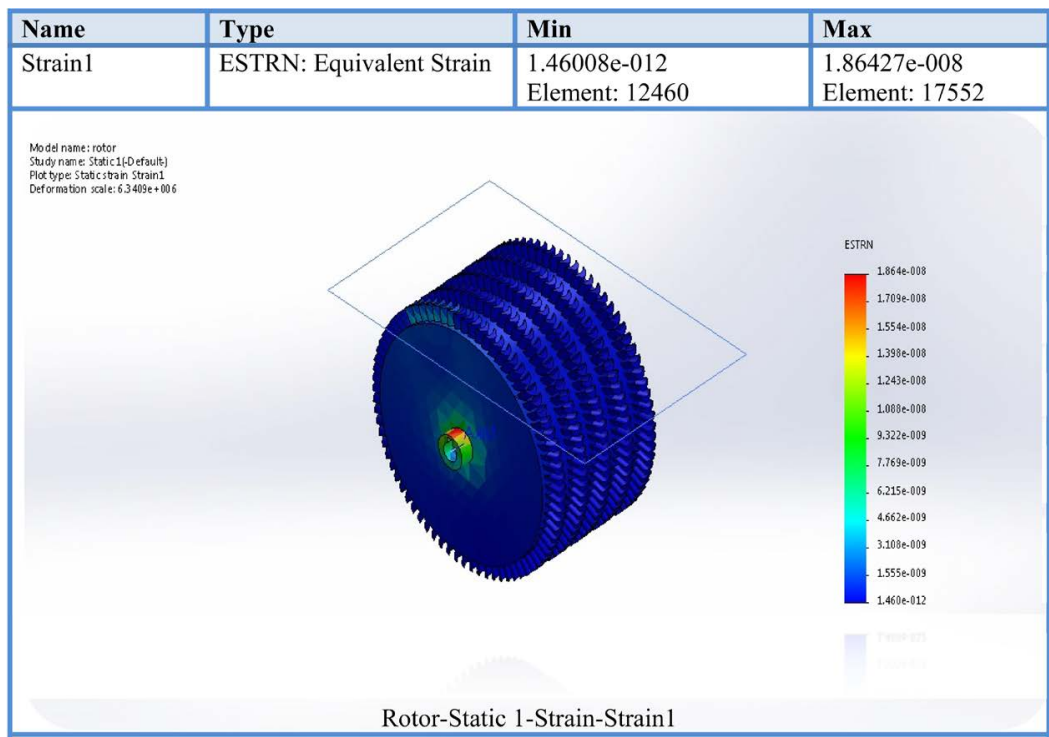

Figure 7. Strain/stress simulation analysis on the turbine rotor. 


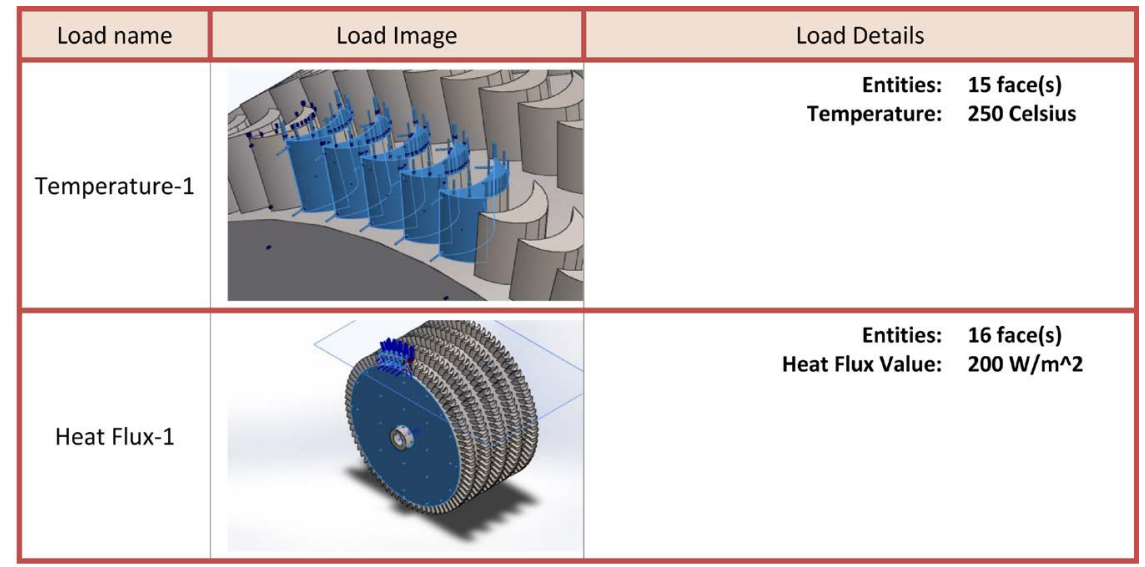

Figure 8. Stress/heat simulation analysis on the turbine rotor and blades.

led to variation in efficiency of the stator profile (Figure 9). The least efficiency (40\%) was found with the modified airfoil on stator and rotor, while the rotor axial chord reduction had the highest efficiency (75\%) as compared with the stator count and stator axial chord reductions with relative blade performance shown in Figure 10. Comparing the recorded stresses and yield strength of the materials of the components, a wide margin was observed, which means that the components will serve their intended purposes without failure within the allowable margin (Figure 9). It can be inferred, from the result of comparison, that the design is safe under normal working condition (at displacement range of 0 $\mathrm{mm}$ to $10.2883 \mathrm{~mm}$ ) of the shaft in terms of stress, strain and temperature rise (Figures 6-8), beyond $10.2883 \mathrm{~mm}$ displacement the system is bound to fail (Figure 11).

The simulated results showed that the design is optimized to perform intended functions without any record of failure. The only point of note was that the shaft must not exceed the maximum deflection of $10 \mathrm{~mm}$ under the maximum allowable loading (Figure 11). The danger therein can be averted with improvement in material selection and right choice of loads acting on the system (Table 2). The exploded, assembled, sectioned micro turbine views with their specifications are given in Figures 12-14, respectively. The implementation of the process has enabled realization of the micro turbine that is capable of producing $5 \mathrm{~kW}$ of electric power using the superheated steam from PKS fuelled boiler of $5.5 \mathrm{~kW}$ capacity, as the prime mover. The components of the turbine and the mini power house can be produced using machining and welding techniques and the materials can be sourced locally (Table 2). The cost of production, inclusive of mini power house, is N590,000 or \$1638 in US Dollars (Table 3 ). The cost of production can be greatly reduced by $50 \%$ under mass production regime.

\section{Conclusion}

A steam micro-turbine that can produce up to $5 \mathrm{~kW}$ of electricity has been successfully designed, and validated using Solidworks and Comsol multiphysics 


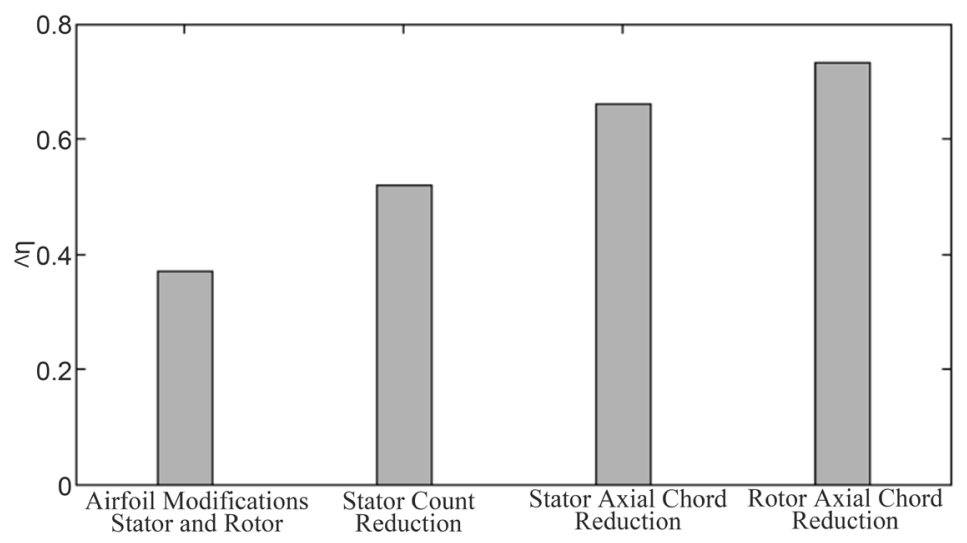

Figure 9. Efficiency measures at varying condition of stator, rotor and blade.

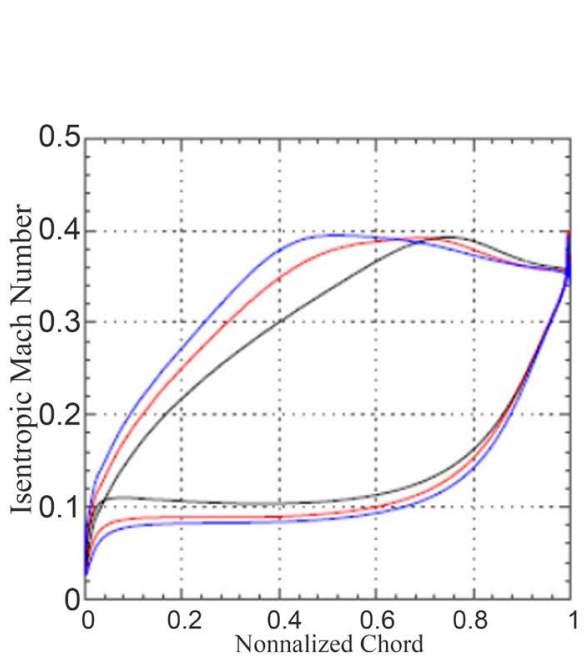

- Modified stator count 60

Modified stator count 50

Modified stator count 50,reduced chord

(a)Blade Loading with modified s/c

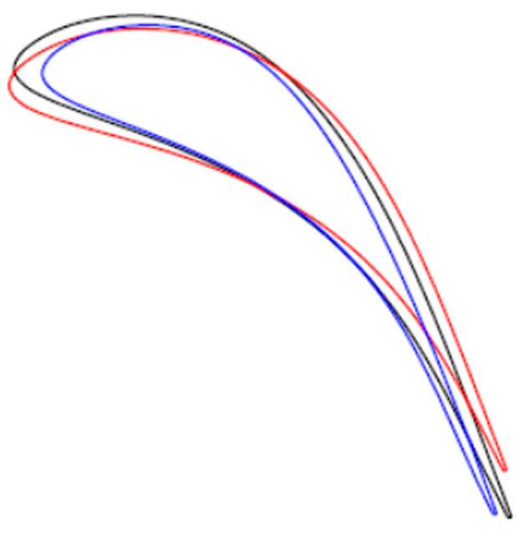

(b)Airfoil Comparison with modified s/c

Figure 10. Stator and blade performance analysis comparison.

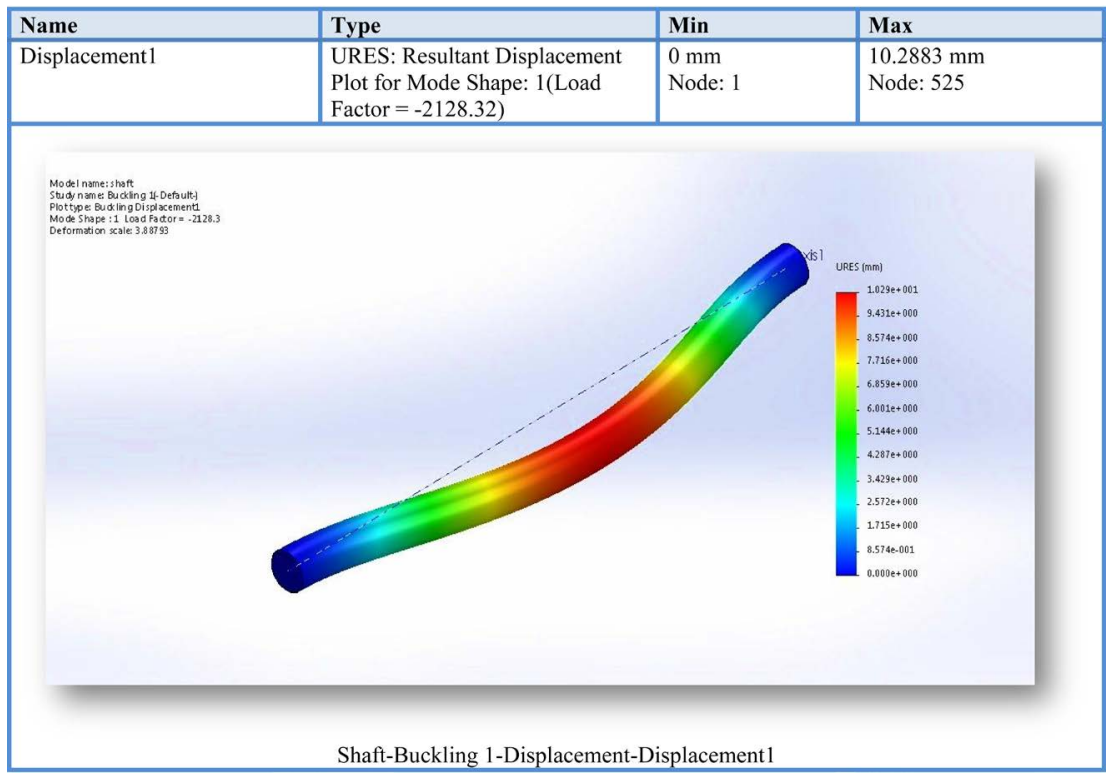

Figure 11. Simulation analysis on turbine shaft. 


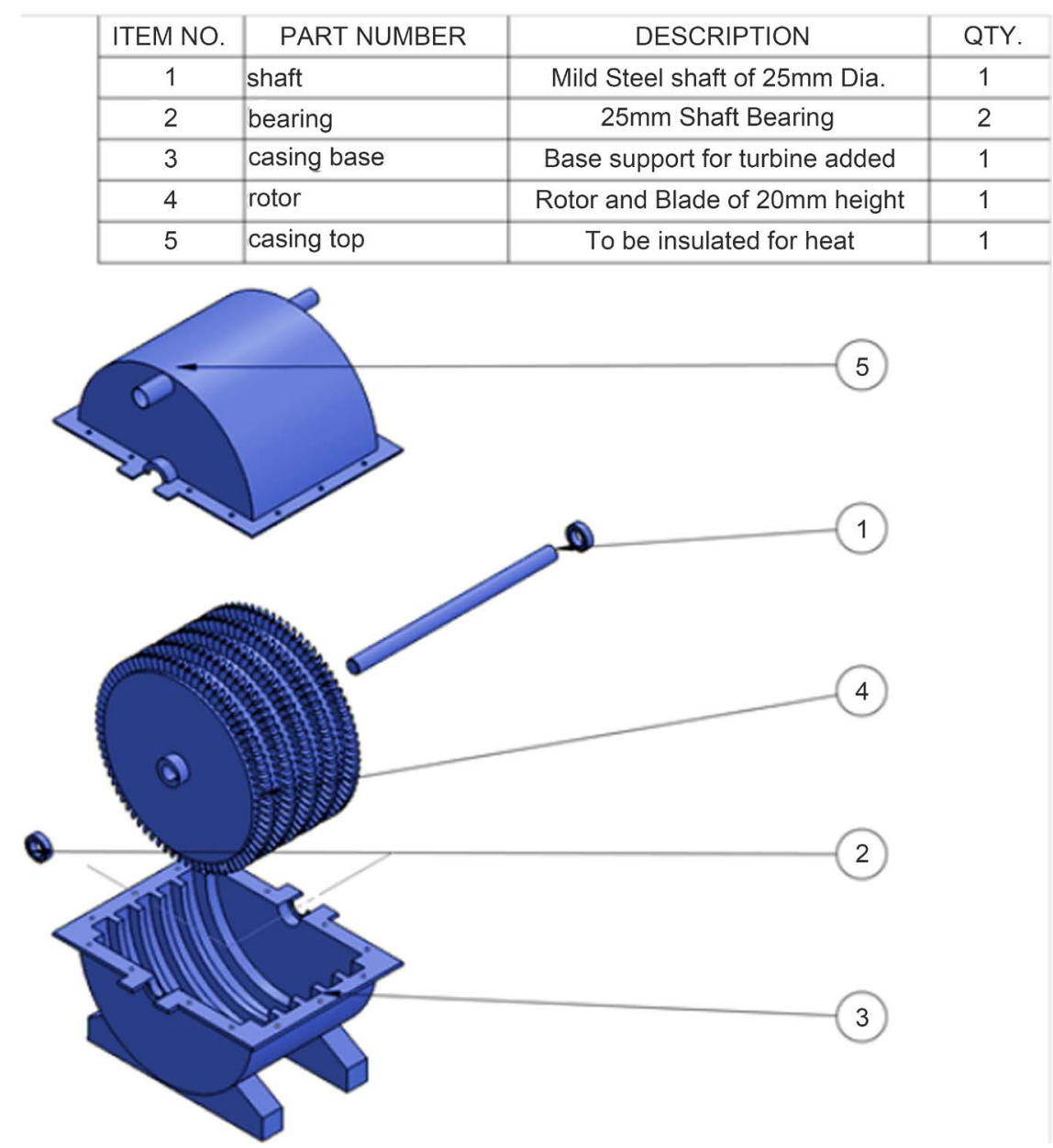

Figure 12. Steam turbine exploded view.

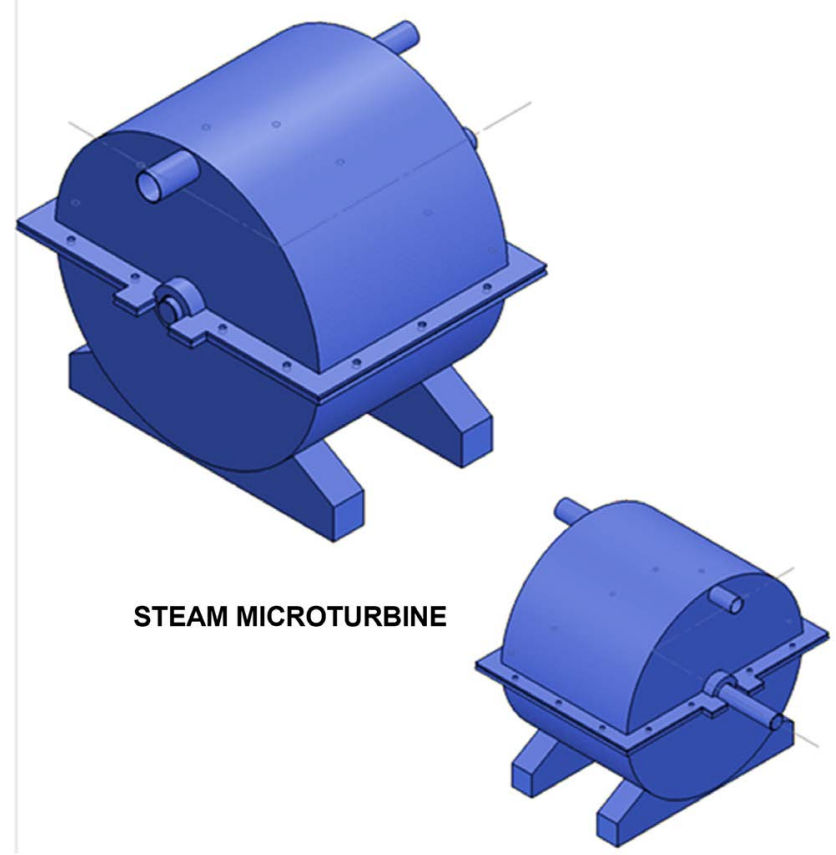

Figure 13. Steam turbine assembly. 


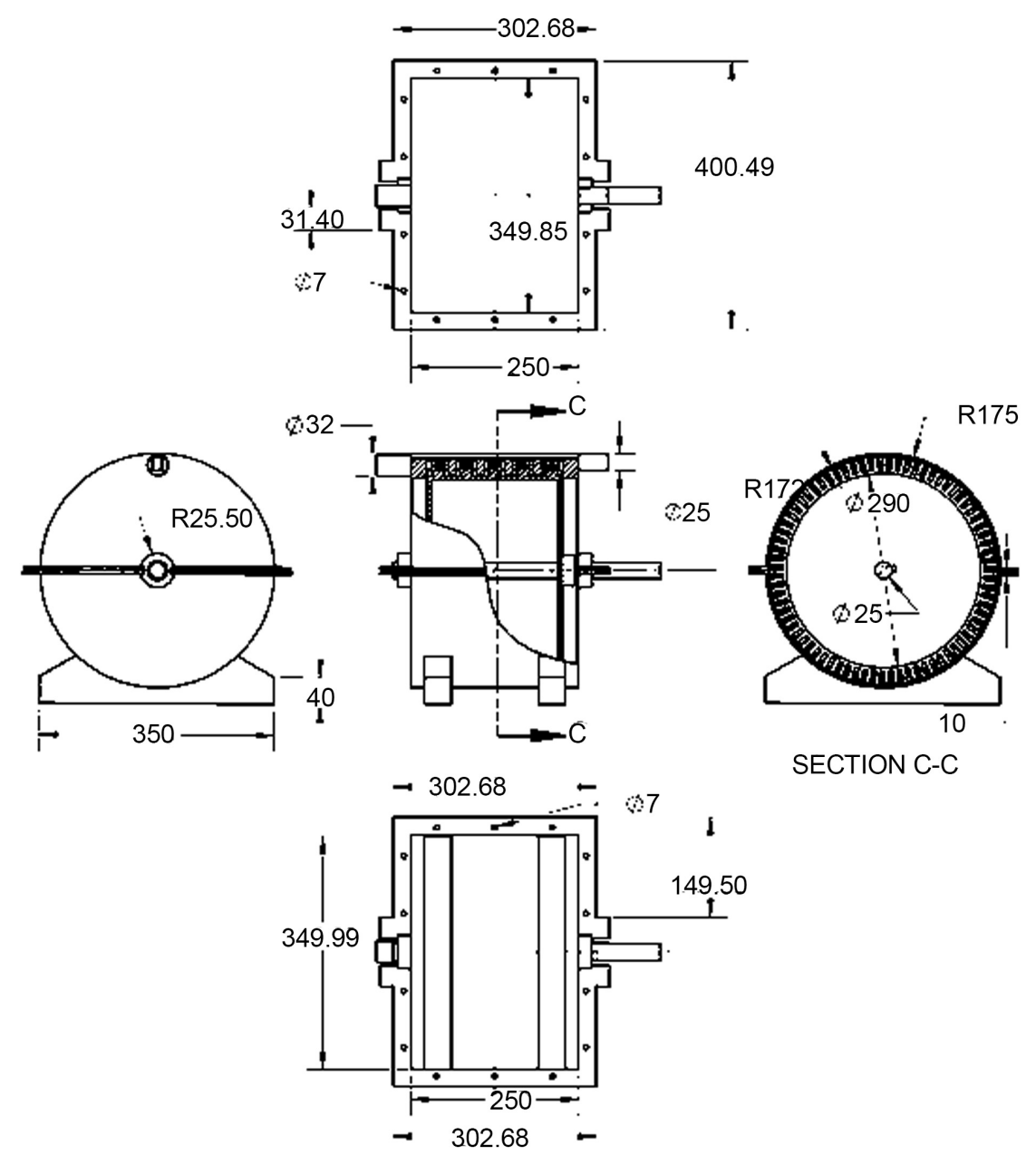

Figure 14. Steam turbine sectional view.

software packages. The design has target providing solution to challenges of regular electric power outage. This has provided a step towards meeting the global millennium goal of attaining industrial level 4.0 through provision of regular and uninterrupted electric power supply by using the process of power generation from locally sourced materials. The study outcomes have been positively disposed towards utilizing steam energy to generate electricity through an articulated steam powered micro turbine designed for the $5 \mathrm{kVA}$ micro power plant. Successfully outcome of the designed has enabled understanding of the power plant components and how well it can be integrated into the energy supply system to boost energy available in the rural and urban cities. Emerging small-scale turbines can improve the power generation and efficiency. The improvement is scalable and can notably turn around to providing energy need of industrialized nations. More inward look and progression are needed in the manufacture of micro-turbines and steam powered machines fuelled with PKS as alternatives to the fossil fuels which are known to be agents of ozone depletion. The importance of steam micro-turbines for power generation cannot be overemphasized in $\mathrm{Ni}$ geria having abundant of PKS as agricultural wastes that can be used as renewa- 
ble energy source for boiler firing. Practical implementation of the design can open a new horizon of enabling innovative means of private power generation to compliment the public supply. Further study focusing improvement in the areas of designing a sustainable gearing system to cater for overloads and insulating system to prevent heat loss should be considered.

\section{Acknowledgements}

Tetfund Nigeria is acknowledged for supporting this research under grant Ref: VCPU/TETFund/155.

\section{Conflicts of Interest}

The authors declare no conflicts of interest regarding the publication of this paper.

\section{References}

[1] Jarosław, M., Marian, P. and Krzysztof, K. (2009) Design Analysis of Turbines for Co-Generating Micro-Power Plant Working in Accordance with Organic Rankine's Cycle. Polish Maritime Research, 16, 34-38.

[2] Lakhoua, M.N. (2012) Causal Analysis and Calculation of the Steam Turbine Efficiency of a Thermal Power Plant. International Journal of Physical Sciences, 7, 5493-5497.

[3] Kareem, B. and Babatunde, D.D. (2018) Optimization of Energy Content of Palm Kernel Shell (PKS) Using Modelling Approach. International Journal of Advance Industrial Engineering, 6, 111-117.

[4] Oladosu, K.O. (2016) Optimization of Combustion of Palm Kernel Shell in a Grate Furnace for Superheated Steam Generation. Ph.D Thesis, Mechanical Engineering Department, Federal University of Technology Akure, Nigeria.

[5] Kareem, B., Oladosu, K.O., Alade, A.O. and Durowoju, M.O. (2018) Optimization of Combustion Characteristics of Palm Kernel-Based Biofuel for Grate Furnace. International Journal of Energy and Environmental Engineering, 9, 457-472. https://doi.org/10.1007/s40095-018-0277-5

[6] Oladosu, K.O., Ajayeoba, A.O., Kareem B. and Akinnuli, B.O. (2018) Development and Cost Estimation for Sizing $5 \mathrm{Kw}$ Palm Kernel Shell Steam Boiler. American Journal of Engineering Research (AJER), 7, 113-122.

[7] Oladosu, K.O., Kareem, B., Akinnuli, B.O. and Asafa, T.B. (2017) Application of Computer Aided Design for Palm Kernel Shell Steam Boiler. Environment-Leonardo Electronic Journal of Practices and Technologies, 30, 87-104.

[8] Oladosu, K.O., Kareem, B., Akinnuli, B.O. and Asafa, T.B. (2017) Development of Computer Program for Design of a Scalable Combustion Furnace Using Palm Kernel Shell as Heat Source. Acta Technica Corviniensis-Bulletin of Engineering, 1 , 127-134.

[9] Oladosu, K.O., Kareem, B., Akinnuli, B.O. and Asafa, T.B. (2016) Optimisation of Ash Yield from Combustion of Palm Kernel Shell and Selected Additives $\left(\mathrm{Al}_{2} \mathrm{O}_{3}\right.$, $\mathrm{CaO}$ and $\mathrm{MgO}$ ) Using D-Optimal Design. Leonardo Electronic Journal of Practices and Technologies, No. 28, 9-18.

[10] Chandra, S.M.R. (2015) Design and Analysis of Steam Turbine Rotor. International Journal of Mechanical Engineering and Technology, 6, 195-201. 
[11] Upendar, S., Hari Brahmaiah, K., Reddy, N.V.R. and Rakesh, B. (2015) Design and Analysis of Micro Steam Turbine Using Catia and Ansys. International Journal of Computational Engineering Research, 5, 27-30.

[12] Chenduran, A., Tharani, S., Chenthooran, G. and Johnson, S. (2010) Design of the Steam Turbine for Small Scale Power Plant.

[13] Balje, O.E. (1981) Turbomachines: A Guide to Design, Selection and Theory. John Wiley \& Sons Inc., Hoboken. https://doi.org/10.1115/1.3241788

[14] Lee, J.F. (1999) Theory and Design of Steam and Gas Turbines. McGraw-Hill Book Company Inc., London.

[15] Singh, M.P., George, M. and Lucas, P.E. (2011) Blade Design and Analysis for Steam Turbines. The McGraw-Hill Companies, Inc., London.

[16] Deshpande, S. (2017) Improved Steam Turbine Design for Optimum Efficiency and Reduced Cost of Ownership. Department of Energy Sciences, Lund University.

[17] Chu, T.L. (1999) Effects of Mach Number and Flow Incidence on Aerodynamic Losses of Steam Turbine Blades.

[18] Jansohn, P. (2013) Modern Steam Turbine Systems: High Efficiency, Low Emission, Fuel Flexible Power Generation. 1st Edition, Woodhead Publishing, Sawston, Cambridge. https://doi.org/10.1533/9780857096067

[19] Reddy, A.A.S., Kumar, T.S., Krishna Reddy, A.V. and Prathibha, V.V. (2014) Analysis of Steam Turbines, 32-48. 